\title{
Evaluation of neurotoxic and neuroprotective pathways affected by antiepileptic drugs in cultured hippocampal neurons
}

\author{
Maria I. Morte ${ }^{\mathrm{a}, \mathrm{b}}$, Bruno P. Carreira a ${ }^{\mathrm{a}}$, Maria J. Falcão ${ }^{\mathrm{a}}$, António F. Ambrósio ${ }^{\mathrm{a}, \mathrm{c}}$, Patrício Soares-da-Silva ${ }^{\mathrm{d}, \mathrm{e}}$, \\ Inês M. Araújo ${ }^{\mathrm{a}, \mathrm{f}, \mathrm{g}}$, Caetana M. Carvalho ${ }^{\mathrm{a}, \mathrm{b}, *}$ \\ ${ }^{a}$ Center for Neuroscience and Cell Biology, University of Coimbra, Coimbra, Portugal \\ ${ }^{\mathrm{b}}$ Department of Life Sciences, Faculty of Science and Technology, University of Coimbra, Coimbra, Portugal \\ ${ }^{c}$ Centre of Ophthalmology and Vision Sciences, IBILI, Faculty of Medicine, University of Coimbra, Coimbra, Portugal \\ ${ }^{\mathrm{d}}$ Department of Pharmacology and Therapeutics, Faculty of Medicine, University of Porto, Porto, Portugal \\ ${ }^{\mathrm{e}}$ Department of Research and Development, BIAL, S. Mamede do Coronado, Portugal \\ ${ }^{\mathrm{f}}$ Regenerative Medicine Program, Department of Biomedical Sciences and Medicine, University of Algarve, Faro, Portugal \\ ${ }^{\mathrm{g}}$ IBB-Institute for Biotechnology and Bioengineering, Center for Molecular and Structural Biomedicine, University of Algarve, Faro, Portugal
}

\section{A R T I C L E I N F O}

\section{Article history:}

Received 16 January 2013

Accepted 11 September 2013

Available online 19 September 2013

\section{Keywords:}

Eslicarbazepine

Carbamazepine

Oxcarbazepine

Lamotrigine

Valproate

Neurotoxicity

\begin{abstract}
A B S T R A C T
In this study we evaluated the neurotoxicity of eslicarbazepine acetate (ESL), and of its in vivo metabolites eslicarbazepine (S-Lic) and R-licarbazepine (R-Lic), as compared to the structurally-related compounds carbamazepine (CBZ) and oxcarbazepine (OXC), in an in vitro model of cultured rat hippocampal neurons. The non-related antiepileptic drugs (AEDs) lamotrigine (LTG) and sodium valproate (VPA) were also studied. We assessed whether AEDs modulate pro-survival/pro-apoptotic pathways, such as extracellularregulated kinase (ERK1/2), Akt and stress activated protein kinase/c-Jun N-terminal kinase (SAPK/JNK).

We found that neither ESL nor its metabolites, CBZ or LTG, up to $0.3 \mathrm{mM}$, for $24 \mathrm{~h}$ of exposure, decreased cell viability. OXC was the most toxic drug decreasing cell viability in a concentration-dependent manner, leading to activation of caspase-3 and PARP cleavage. VPA caused the appearance of the apoptotic markers, but did not alter cell viability. ESL, S-Lic and OXC decreased the levels of phosphoERK1/2 and of phospho-Akt, when compared to basal levels, whereas CBZ decreased phospho-SAPK/ JNK and phospho-Akt levels. LTG and VPA increased the phosphorylation levels of SAPK/JNK.

These results suggest that ESL and its main metabolite S-Lic, as well as CBZ, LTG and VPA, are less toxic to hippocampal neurons than OXC, which was the most toxic agent.
\end{abstract}

(c) 2013 Elsevier Ltd. All rights reserved.

\section{Introduction}

A number of antiepileptic drugs (AEDs) are available for the treatment of epilepsy, bipolar disorder, migraine, mania, neuropathic pain, schizophrenia and anxiety (Rogawski and Loscher, 2004; Stefan and Feuerstein, 2007). However, some AEDs are endowed with unfavourable safety profiles, such as hepatotoxicity,

\footnotetext{
Abbreviations: AEDs, antiepileptic drugs; AIF, apoptosis-inducing factor; BCA, bicinchoninic acid; BSA, bovine serum albumin; CBZ, carbamazepine; CNS, central nervous system; DTT, dithiothreitol; ESL, eslicarbazepine acetate; S-Lic, S-licarbazepine; ERK, extracellular signal-regulated kinase; GABA, gamma-aminobutyric acid; LTG, lamotrigine; MAPK, mitogen-activated protein kinase; OXC, oxcarbazepine; PARP, poly-ADP ribose polymerase; PBS, phosphate-buffered saline; PMSF, phenylmethylsulphonyl fluoride; R-Lic, R-licarbazepine; SAPK/JNK, stress-activated protein kinase/c-Jun $\mathrm{N}$-terminal kinase; SDS, sodium dodecyl sulphate; TBS, trisbuffered saline; Thr, threonine; Tyr, tyrosine; VPA, valproate.

* Corresponding author at: Center for Neuroscience and Cell Biology, University of Coimbra, Coimbra, Portugal. Tel.: +351 239820190; fax: +351 304502930 .

E-mail address: cmcarv@cnc.uc.pt (C.M. Carvalho).
}

toxicity to central nervous system (CNS) and show complex drug/drug interactions (Johannessen Landmark and Patsalos, 2010; Loring et al., 2007; Pennell, 2008). In recent years, pharmaceutical companies have developed new AEDs with improved safety profiles than the previously available ones. Several studies have described the toxicity of AEDs to neuronal cells, in vitro and in vivo, (Bittigau et al., 2002; Chateauvieux et al., 2010; Landmark and Johannessen, 2008; Manent et al., 2008), but the mechanisms underlying the toxic effects of AEDs in neuronal cells are still a matter of debate.

Carbamazepine (CBZ) is one of the most prescribed AED, although it is endowed with considerable adverse effects (Albani et al., 1995; Elger and Bauer, 1998). In the last two decades, two other dibenz[b,f]azepine derivatives were approved as anticonvulsants, first oxcarbazepine (OXC) in 1990 (Elger and Bauer, 1998), and more recently eslicarbazepine acetate (ESL) in 2009 (Elger et al., 2009; McCormack and Robinson, 2009). Both drugs were developed with the aim to improve efficacy and tolerability 
(Landmark and Johannessen, 2008). These dibenz[b,f]azepine derivatives, CBZ, OXC and ESL, are structurally related and exert their primary antiseizure activity by blocking voltage-gated sodium channels (VGSC) in neuronal membranes that are responsible for action-potential generation (Parada and Soares-da-Silva, 2002). Despite not being their main targets, these AEDs also act on other receptors, such as the metabotropic receptors that are involved in intracellular signaling pathways (Bittigau et al., 2002), pointing to the relevance of studying their possible effects on pro-apoptotic/ pro-survival pathways.

OXC and ESL were developed as structural derivatives of $\mathrm{CBZ}$, but there are striking differences in their metabolism, mainly between CBZ and ESL. ESL is structurally different at the 10,11-position, and consequently, it is not metabolized to CBZ-10,11-epoxide and, therefore, it is not susceptible to enzyme induction or autoinduction (Bialer, 2006). Moreover, ESL is a once-daily AED (Almeida and Soares-da-Silva, 2007) that is rapidly absorbed and undergoes extensive first-pass metabolism, in humans (Almeida et al., 2005) and mice (Alves et al., 2007), to its main active metabolite, eslicarbazepine (S-Lic), which is responsible for approximately $95 \%$ of total systemic drug exposure, and to a lesser extent to Rlicarbazepine (R-Lic) and OXC, (Almeida et al., 2005). Our group previously demonstrated that ESL is less toxic to cultured neurons than CBZ and OXC, namely at high concentrations $(0.3 \mathrm{mM})$. Indeed, ESL did not induce apoptosis or caused structural damage to the neuritic network (Ambrosio et al., 2000; Araujo et al., 2004), whereas CBZ was found to induce apoptosis in cultured cerebellar granule cells (Gao et al., 1995; Nonaka et al., 1998) and OXC increased the activity of caspase-3-like enzyme (Ambrosio et al., 2000). However, the effect of ESL metabolites, S-Lic and R-Lic, on the viability of neuronal cells, has not been addressed yet, and it is of interest to determine the direct effects of S-Lic and R-Lic on the viability of cultured neurons, since in the in vitro system (cultured neurons) there is no metabolism of ESL as it occurs in vivo.

Lamotrigine (LTG) also exerts its anticonvulsive action by blocking voltage-gated sodium channels, but is chemically unrelated to any of the above referred AEDs (Kuo, 1998; Xie et al., 1995). LTG was approved in the United States in 1994 and is an effective and well-tolerated drug with few adverse effects and low toxicity at CNS. In the neonatal rat brain, LTG did not induce neuronal apoptosis (Katz et al., 2007) and has been reported to have neuroprotective effects (Willmore, 2005).

Valproate (VPA), first approved in Europe in the early 1960s, has become the most prescribed AED worldwide despite its debatable effectiveness (Perucca, 2002). It is a broad spectrum AED with a simple structure of a short, branched fatty acid but with various mechanisms of action. VPA enhances GABAergic neurotransmission (Johannessen and Johannessen, 2003; Loscher, 2002), modulates brain metabolism, decreases excitability by affecting intracellular signaling pathways (Rogawski and Loscher, 2004), and affects voltage-gated sodium, potassium and calcium channels (Johannessen and Johannessen, 2003). VPA induces apoptotic neurodegeneration in the developing rat brain and reduces the levels of phosphorylated ERK 1/2 and Akt (Bittigau et al., 2003). Recently, Wang and colleagues (2012) showed that VPA selectively induces apoptosis in neurons in mixed neuron-astrocyte cultures from human fetal neural progenitors (Wang et al., 2012). However, in vitro studies described opposite effects of VPA, showing that VPA promotes the phosphorylation of ERK $1 / 2$, Akt and SAPK/JNK, which may ultimately be responsible for its neuroprotective effects (Chuang, 2005; Di Daniel et al., 2005; Mora et al., 1999).

In the present study, we compared the effects of ESL, of its metabolites S-Lic and R-Lic, and the structurally-related compounds CBZ and OXC, as well as those of the non-related compounds LTG and VPA, on the survival of primary cultures of rat hippocampal neurons and addressed possible mechanisms underlying their neurotoxic effects. We also assessed whether the AEDs modulate pro-survival/pro-apoptotic pathways such as extracellular-regulated kinase (ERK1/2), Akt and stress activated protein kinase/c-Jun N-terminal kinase (SAPK/JNK) signaling pathways. This work contributes to clarifying some of the mechanisms involved on the effects of AEDs on neuronal viability in an in vitro model of cultured hippocampal neurons.

\section{Material and methods}

\subsection{Animals}

Wistar rats were obtained from Charles River (Barcelona, Spain) and kept in our animal facilities (Faculty of Medicine, University of Coimbra, Portugal), in a room with controlled temperature $\left(21^{\circ} \mathrm{C} \pm 1^{\circ} \mathrm{C}\right)$ and humidity (55\%), with food and water ad libitum in a $12 \mathrm{~h}$ dark:light cycle. All experiments were performed in accordance with Institutional and European guidelines (86/609/ EEC) for the care and use of laboratory animals.

\subsection{Primary rat hippocampal cultures}

Hippocampal neurons were dissociated from the hippocampus of E17-E18 Wistar rat embryos, after treatment with trypsin $\left(2.0 \mathrm{mg} / \mathrm{ml}, 15 \mathrm{~min}, 37^{\circ} \mathrm{C}\right)$ and deoxyribonuclease I (DNase I, $0.15 \mathrm{mg} / \mathrm{ml}$ ) in calcium- and magnesium-free Hank's balanced salt solution $\left(137 \mathrm{mM} \mathrm{NaCl}, 5.36 \mathrm{mM} \mathrm{KCl}, 0.44 \mathrm{mM} \mathrm{KH}_{2} \mathrm{PO}_{4}, 0.34 \mathrm{mM}\right.$ $\mathrm{Na}_{2} \mathrm{PO}_{4} \cdot 2 \mathrm{H}_{2} \mathrm{O}, 4.16 \mathrm{mM} \mathrm{NaHCO}_{3}, 5 \mathrm{mM}$ glucose, $1 \mathrm{mM}$ sodium pyruvate, $10 \mathrm{mM}$ HEPES, $\mathrm{pH}$ 7.4). The cells were cultured in serum-free Neurobasal medium, supplemented with B27 supplement, glutamate $(25 \mu \mathrm{M})$, gentamicin $(0.12 \mathrm{mg} / \mathrm{ml})$, as described previously (Ambrosio et al., 2000; Araujo et al., 2004; Brewer et al., 1993) and GlutaMAX TM $(0.5 \mathrm{mM})$. Cultures were kept at $37^{\circ} \mathrm{C}$ in a humidified incubator in $5 \% \mathrm{CO}_{2} / 95 \%$ air, for $7-8$ days. The cells were plated on poly-D-lysine-coated $(0.1 \mathrm{mg} / \mathrm{ml})$ multiwells at a density of $0.1 \times 10^{6}$ cells $/ \mathrm{cm}^{2}$ for cell viability studies and Western blot analysis, and plated on glass coverslips at a density of $0.075 \times 10^{6}$ cells $/ \mathrm{cm}^{2}$ for immunocytochemistry.

\subsection{Exposure of hippocampal neurons to the drugs}

The hippocampal neurons were exposed to AEDs for $24 \mathrm{~h}$, as previously described (Ambrosio et al., 2000; Araujo et al., 2004), or for other periods as indicated in the figure legends. The drugs were prepared in DMSO (except VPA, which was prepared in water), and further diluted in $200 \mu$ laliquots of culture medium taken from each well and then added back to the correspondent well. In control conditions, the same concentrations of DMSO were utilized for all the situations tested and did not affect cell viability.

\subsection{Analysis of cell viability and nuclear morphology}

Cell viability was assessed in cultured hippocampal neurons, following treatment with different concentrations of AEDs for $24 \mathrm{~h}$, using the resazurin reduction assay, as described previously (Araujo et al., 2007). Briefly, resazurin reduction was measured spectrophotometrically at 570 and $600 \mathrm{~nm}$, following incubation of the cells with $300 \mu \mathrm{l}$ of $10 \%$ resazurin in Krebs buffer $(132 \mathrm{mM}$ $\mathrm{NaCl}, 4 \mathrm{mM} \mathrm{KCl}, 1.4 \mathrm{mM} \mathrm{MgCl}_{2}, 1 \mathrm{mM} \mathrm{CaCl} 2,6 \mathrm{mM}$ glucose, $10 \mathrm{mM}$ Hepes-Na, pH 7.4), for $2 \mathrm{~h}$ at $37^{\circ} \mathrm{C}$, in the dark. All experiments were carried out in triplicate, and the results are expressed as percentage of control. Cell death was also assessed by evaluating the degree of nuclear condensation/fragmentation, after nuclear labeling with Hoechst 33342, as described below. 


\subsection{Preparation of lysates of cultured hippocampal neurons}

The cells were washed and lysed at $4{ }^{\circ} \mathrm{C}$ in $50 \mathrm{mM} \mathrm{KCl}, 50 \mathrm{mM}$ PIPES, 10 mM EGTA, 2 mM MgCl , 0.5\% Triton X-100, supplemented with $100 \mu \mathrm{M}$ phenylmethylsulphonyl fluoride, $1 \mathrm{mM}$ dithiothreitol, $1 \mu \mathrm{g} / \mathrm{ml}$ chymostatin, $1 \mu \mathrm{g} / \mathrm{ml}$ leupeptin, $1 \mu \mathrm{g} / \mathrm{ml}$ antiparin, $5 \mu \mathrm{g} / \mathrm{ml}$ pepstatin $\mathrm{A}, 1 \mu \mathrm{g} / \mathrm{ml}$ orthovanadate, $10 \mu \mathrm{g} / \mathrm{ml} \mathrm{NaF}, \mathrm{pH}$ 7.4 , at $4{ }^{\circ} \mathrm{C}$. Protein concentration was determined by the bicinchoninic acid (BCA) method (BCA ${ }^{\mathrm{TM}}$ Protein Assay kit, Pierce, Fisher Scientific, Loures, Portugal), and the samples were denatured following addition of $6 \mathrm{x}$ concentrated sample buffer $(0.5 \mathrm{M}$ Tris, $30 \%$ glycerol, 10\% SDS, 0.6 M DTT, 0.012\% bromophenol blue). After heating for $5 \mathrm{~min}$ at $95^{\circ} \mathrm{C}$, the samples were stored at $-20^{\circ} \mathrm{C}$ until analysis.

\subsection{Western blot analysis}

Following lysis and denaturation of the samples, equal amounts of protein were separated by electrophoresis on sodium dodecyl sulphate polyacrylamide gels, and transferred electrophoretically to polyvinylidene difluoride membranes. These were then blocked for $1 \mathrm{~h}$ at room temperature in Tris-buffered saline $(137 \mathrm{mM} \mathrm{NaCl}$, $20 \mathrm{mM}$ Tris- $\mathrm{HCl}, \mathrm{pH}$ 7.6) containing $0.1 \%$ Tween 20 (TBS-T) and $5 \%$ non-fat milk (or 3\% BSA, for the analysis of phospho-proteins). All primary antibodies used were from Cell Signaling (Danvers, MA, USA) as follows: rabbit anti-cleaved poly ADP-ribose polymerase (PARP), 1:1000; rabbit anti-cleaved caspase-3 1:1000; rabbit anti-phospho SAPK/JNK (Thr183/Tyr185) 1:1000, rabbit antiSAPK/JNK, 1:1000; rabbit anti-phospho p44/p42 MAPK (ERK 1/2) (Thr202/Tyr204) 1:1000; mouse anti-p44/42 MAPK (ERK 1/2) (3A7) 1:2000; rabbit phospho-Akt (Ser473) 1:1000, rabbit phospho-Akt (Thr308) 1:1000; and rabbit anti-Akt (pan) (11E7) $1: 1000$, in TBS-T $1 \%$ non-fat milk (or 1\% BSA for phospho-proteins), and were incubated overnight, at $4{ }^{\circ} \mathrm{C}$. After extensive rinsing in TBS-T, the membranes were incubated for $1 \mathrm{~h}$ at room temperature with an alkaline phosphatase-linked secondary antibody (antimouse or anti-rabbit IgG $1: 20,000$ ) in TBS-T $1 \%$ non-fat milk (or $0.5 \%$ BSA for phospho-proteins). Immunoreactive bands were visualized with ECF in a VersaDoc 3000 imaging system (BioRad, Amadora, Portugal), following incubation of the membrane with the ECF reagent for $5 \mathrm{~min}$. Protein loading controls were either performed using antibodies against the total protein in study (total ERK $1 / 2$, total Akt and total SAPK/JNK), or against $\alpha$-tubulin $(55 \mathrm{kDa})(1: 10,000)$.

\subsection{Immunocytochemistry}

The culture medium was removed from the primary hippocampal cultures, the cells were rinsed three times with phosphate-buffered saline (PBS), and then fixed with $4 \%$ paraformaldehyde, at room temperature, for $20 \mathrm{~min}$. Non-specific binding was blocked with $3 \%$ BSA in PBS for $1 \mathrm{~h}$. Cells were incubated with the primary antibody for $90 \mathrm{~min}$, at room temperature. After rinsing with PBS, the cells were incubated with the appropriate secondary antibody for $1 \mathrm{~h}$ (1:200, anti-rabbit IgGs conjugated with Alexa Fluor 594) at room temperature. All antibodies were prepared in blocking solution. Nuclei were counterstained with Hoechst $33342(2 \mu \mathrm{g} / \mathrm{ml})$ for 5 min, followed by rinsing in PBS. The coverslips were mounted on Dako fluorescent mounting medium in microscopy glass slides, and images were acquired in a laser scanning confocal microscope (LSM 510 META, Zeiss). Cells from seven to ten randomly selected fields of each coverslip were counted using Photoshop (version CS3; ASI, CA, USA), which represents approximately 900-1,200 cells per coverslip. Data was expressed as percentage of the total number of nuclei, counterstained with Hoechst 33342. The primary antibody and dilution used was: rabbit anti-apoptosis-induncing factor (AIF) antibody, 1:100 (Cell Signaling, Isaza, Carnaxide, Portugal).

\subsection{Data analysis}

Data are expressed as means \pm SEM. Statistical significance was determined by one-way analysis of variance (ANOVA), followed by Dunnett's post-test, and two-way analysis of variance (ANOVA), followed by Bonferroni's post-test.

\subsection{Materials}

ESL, S-Lic, R-Lic, OXC and CBZ were obtained from BIAL-Portela \& C- S.A. (S. Mamede do Coronado, Portugal). NEUROBASAL ${ }^{\text {TM }}$ Medium, B27 supplement, GlutaMAX ${ }^{\mathrm{TM}}$, trypsin and gentamicin were purchased from GIBCO $^{\circledR}$ (Invitrogen ${ }^{\mathrm{TM}}$, Alfagene, Carcavelos, Portugal). Deoxyribonuclease 1 (DNase-1), resazurin, PMSF, dithiothreitol, chymostatin, leupeptin, antipain, pepstatin A and trypan blue were purchased from Sigma-Aldrich (Madrid, Spain). LTG and VPA were obtained from Tocris Bioscience (Biogen Scientifca, S.L., Madrid, Spain). Bovine serum albumin was obtained from Calbiochem (VWR, Carnaxide, Portugal). Hoechst 33342 and anti-rabbit IgGs labeled with Alexa Fluor 594 were purchased from Molecular Probes $^{\circledR}$ (Invitrogen ${ }^{\mathrm{TM}}$, Alfagene, Carcavelos, Portugal). PVDF membranes and the Enhanced Chemifluorescence (ECF) reagent were obtained from Amersham Pharmacia Biotech (GE Healthcare, Carnaxide, Portugal). Other reagents used in immunoblotting experiments were purchased from BioRad (Sintra, Portugal).

\section{Results}

\subsection{Evaluation of the toxicity profile of antiepileptic drugs in cultured hippocampal neurons}

We first investigated whether ESL and its metabolites, S-Lic and R-Lic, as well as the other AEDs affect cell viability. Cultured hippocampal neurons were exposed to the AEDs for $24 \mathrm{~h}$, at concentrations of $0.01,0.03,0.1$ and $0.3 \mathrm{mM}$ (for ESL, S-Lic, R-Lic, CBZ, OXC and LTG) and of $0.01,0.03,0.1,0.3,0.5,1$ and $3 \mathrm{mM}$ for VPA. The concentrations of the AEDs that were utilized in these study are within the range of those tested in functional assays using rat hippocampal neurons, namely for the evaluation of effects upon $\mathrm{Ca}^{2+}$ and $\mathrm{Na}^{+}$channels (Ambrosio et al., 1999; Ambrosio et al., 2000; Brady et al., 2011; Hebeisen et al., 2011) and in hippocampal neural progenitor cells (Hsieh et al., 2004).

The viability of hippocampal neurons determined after exposure to ESL or its metabolites (for all the concentrations tested) was not significantly altered comparing to control conditions (Fig. 1A-C). Furthermore, treatment of hippocampal neurons with CBZ or LTG did not significantly affect neuronal viability for the concentrations tested (Fig. 1D and F). VPA, which is both chemically and pharmacologically unrelated to the dibenz[b,f]azepine derivatives, also did not alter the viability of the hippocampal neurons (Fig. 1G). However, OXC significantly changed the viability of hippocampal neurons, in a concentration-dependent manner, decreasing cell viability to $93.2 \pm 2.3 \%(p<0.05)$ and $86.3 \pm 2.9 \%$ $(p<0.01)$ of the control, for 0.1 and $0.3 \mathrm{mM}$, respectively (Fig. 1E). Lower concentrations of OXC $(0.01$ and $0.03 \mathrm{mM})$ did not affect cell viability. The observed toxic effects caused by high concentrations of OXC on the hippocampal neurons are in agreement with previous studies (Ambrosio et al., 2000; Araujo et al., 2007).

Nuclear condensation/fragmentation, which is a hallmark of cell death, was next analysed in cultured hippocampal neurons exposed to AEDs for $24 \mathrm{~h}$, for the higher concentration tested in the 
A

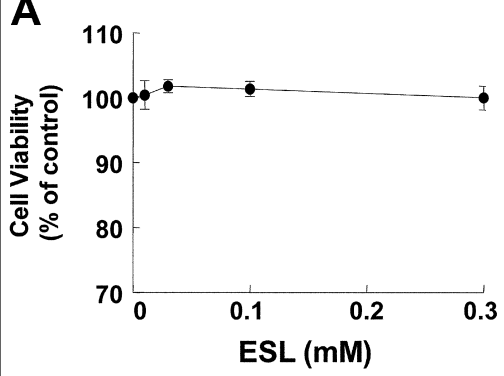

C

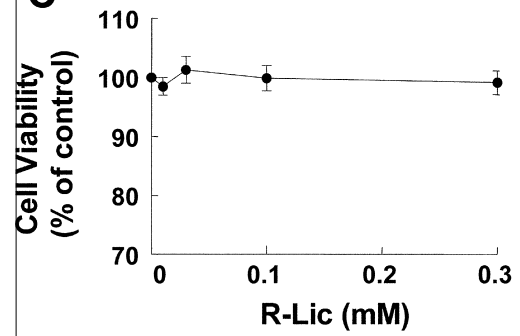

E

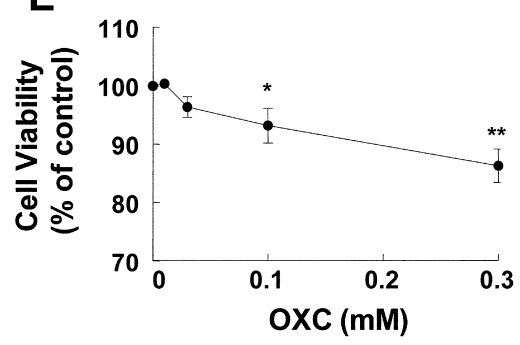

B

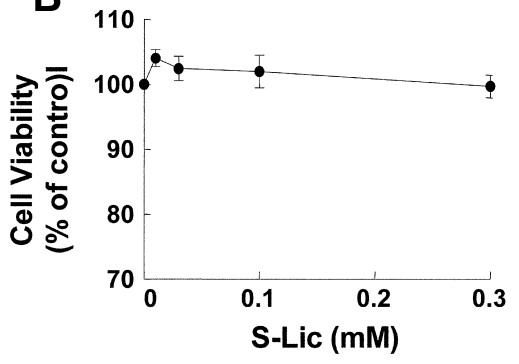

D

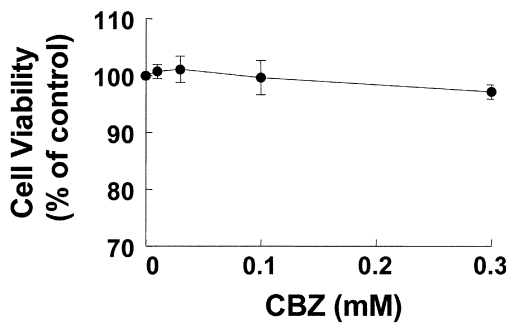

$\mathbf{F}$

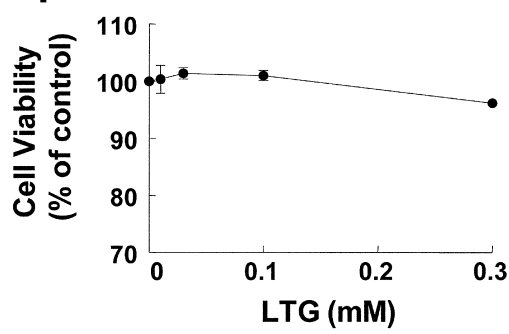

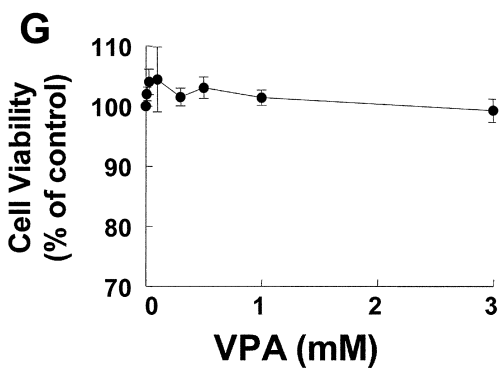

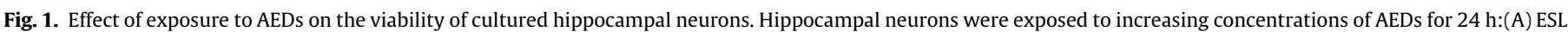

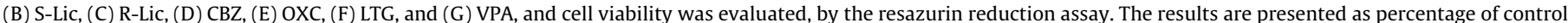

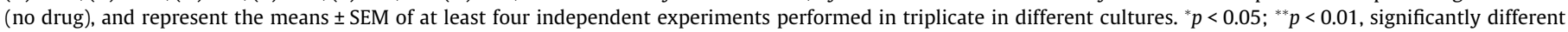

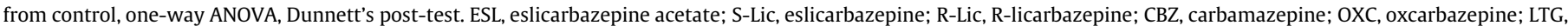
lamotrigine; VPA, valproate.

resazurin assay (0.3 $\mathrm{mM}$, for all AEDs, and $3 \mathrm{mM}$ for VPA). In control cultures, $21.4 \pm 1.4 \%$ of total cells presented condensed/fragmented nuclei, which is in agreement to previous studies showing similar basal levels of cell death in hippocampal cultures (Almeida et al., 2005; Araujo et al., 2007). Exposure to ESL, S-Lic, RLic, CBZ, LTG or VPA did not increase the percentage of condensed/ fragmented nuclei $(p>0.05)$ (Supplementary data, Fig. 1). However, treatment with OXC $(0.3 \mathrm{mM})$ significantly increased the percentage of cells showing nuclear condensation/fragmentation to $37.1 \pm 6.0 \%(p<0.01)$ (Supplementary data, Fig. 1B).

\subsection{Cell exposure to OXC or VPA increased apoptotic markers in cultured hippocampal neurons}

We next investigated the presence of apoptotic markers, such as activation of caspase-3, the main effector caspase in apoptotic cell death, which is activated by proteolytic cleavage of full-length caspase-3 (32 kDa), producing fragments of 17/19 kDa. The presence of these fragments can be used as a marker for caspase- 3 activation. For this purpose, an antibody that selectively recognizes the breakdown products (17/19 kDa), but not full-length caspase-3, was used. Cultured hippocampal neurons were exposed to the AEDs for $24 \mathrm{~h}$ at $0.3 \mathrm{mM}$ (except for VPA that was used at $3 \mathrm{mM}$ ). We detected cleavage of caspase- 3 in cultures exposed to OXC or VPA. Treatment with OXC caused a 5-fold increase in cleaved caspase-3 levels $(p<0.001)$, whereas VPA caused a 2-fold $(p<0.01)$ increase, when compared to the control (Fig. 2). Exposure of the cells to ESL, S-Lic, R-Lic, CBZ or LTG, did not increase the cleavage of caspase-3, as detected by Western blotting.

PARP is a downstream substrate of caspase- 3 and a powerful effector of cell death, causing ATP depletion; the presence of an $89 \mathrm{kDa}$ fragment is indicative of PARP cleavage. We next investigated the profile of PARP cleavage in neurons treated with the AEDs. Cell exposure to OXC or VPA, but not to the other AEDs, 


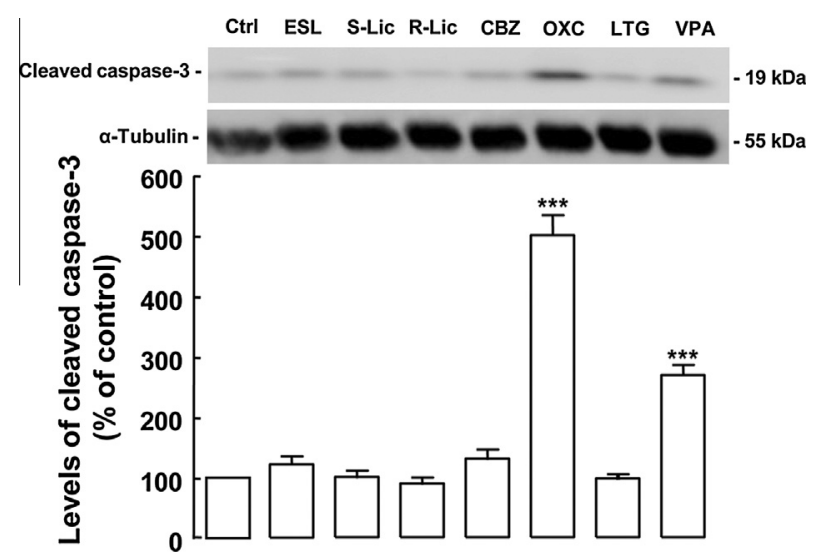

Fig. 2. Levels of cleaved caspase-3 in hippocampal neurons following exposure to AEDs. Hippocampal neurons were exposed for $24 \mathrm{~h}$ to AEDs $(0.3 \mathrm{mM}$ for all AEDs and $3 \mathrm{mM}$ for VPA). Representative Western blots and quantification of the levels of the $17 / 19 \mathrm{kDa}$ cleavage product of caspase- 3 are shown. Levels of cleaved caspase- 3 were significantly higher in cultures treated with OXC and VPA than in control (Ctrl). $\alpha$-Tubulin (55 kDa) was used as a loading control. The results are presented as percentage of control, and represent means \pm SEM of at least 4 independent experiments performed in different cultures. ${ }^{* * *} p<0.001$, significantly different from control, one-way ANOVA, Dunnett's post-test. Abbreviations of the AEDs as indicated in the legend of Fig. 1.

caused PARP cleavage, which increased to $212.1 \pm 39.1 \%(p<0.001)$ and to $218.0 \pm 23.2 \%(p<0.01)$ of the control, respectively, as evaluated by Western blot analysis (Fig. 3 ).

Translocation of AIF from the mitochondria to the nucleus may occur in the caspase-independent apoptotic pathway (Joza et al., 2001). In AED-treated cultures, AIF was detected by immunocytochemistry in the cytoplasm of either viable or dying neurons. Cells treated with ESL and its metabolites, or the other AEDs, did not show evidence of nuclear translocation of AIF in any case. This factor showed a cytosolic localization even though condensed/fragmented nuclei were quite evident in OXC-treated cells $(0.3 \mathrm{mM})$ (Supplementary data, Fig. 2). Thus, AIF does not appear to be involved in cell death triggered by exposure of hippocampal neurons to OXC, pointing to a caspase-dependent apoptotic pathway induced by this AED.

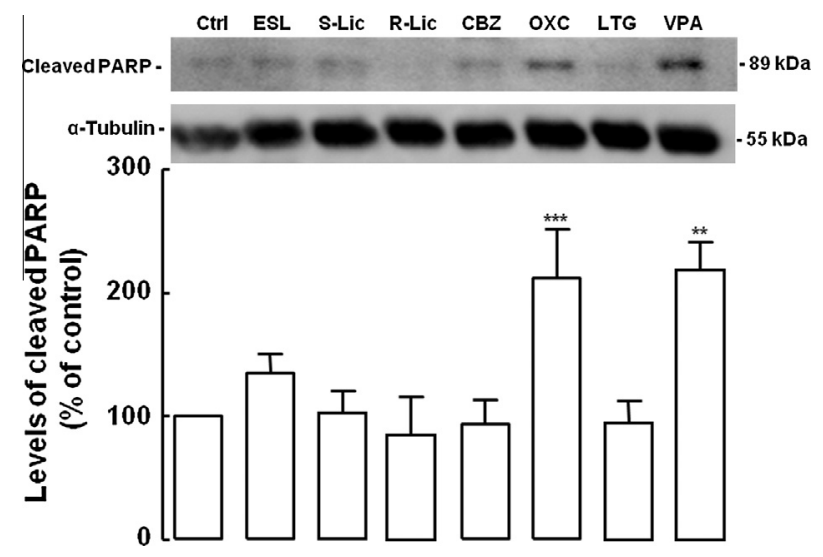

Fig. 3. Levels of cleaved PARP in hippocampal neurons following exposure to AEDs. Hippocampal neurons were exposed for $24 \mathrm{~h}$ to AEDs. The concentrations for each AED were the same as those described in the legend of Fig. 2. Representative Western blots and quantification of the levels of $89 \mathrm{kDa}$ cleavage product of PARP are presented for each AED. Levels of cleaved PARP were significantly higher in cultures treated with OXC and VPA than in control. $\alpha$-Tubulin ( $55 \mathrm{kDa}$ ) was used as a loading control. The results are presented as percentage of control, and represent means \pm SEM of at least 4 independent experiments performed in different cultures. ${ }^{* * *} p<0.001,{ }^{* *} p<0.01$, significantly different from control, one-way ANOVA, Dunnett's post-test. Abbreviations of the AEDs as indicated in the legend of Fig. 1.

\subsection{Effects of antiepileptic drugs on signaling pathways related to neuronal injury/survival}

In order to examine whether the effects of the AEDs presented above are related to changes in pro-survival/pro-apoptotic pathways in cultured hippocampal neurons, we next studied the activation of extracellular-regulated kinase (ERK 1/2; p44/p42), Akt and stress-activated protein kinase/c-Jun $\mathrm{N}$-terminal kinase (SAPK/ JNK; p54/p46). The phosphorylation levels of these kinases were analysed by Western blot at different time points, for short-term exposures up to $60 \mathrm{~min}$, and for a longer period of $24 \mathrm{~h}$ of incubation with each of the AEDs ( $0.3 \mathrm{mM}$ for ESL, S-Lic, R-Lic, CBZ, OXC and LTG; $3 \mathrm{mM}$ for VPA). The phosphorylated forms of those kinases were differently affected, as described below.

In cultured hippocampal neurons exposed to ESL or S-Lic, the levels of phospho-ERK $1 / 2$ decreased, as compared to control conditions (Fig. $4 \mathrm{~A}$ and $\mathrm{B}$ ). The levels of phospho-ERK $1 / 2$ decreased to $39.7 \pm 8.4 \%$ for ESL and to $54.0 \pm 9.8 \%$ for S-Lic $(p<0.01), 60 \mathrm{~min}$ following exposure to the drug. Phosphorylation of ERK $1 / 2$ was still decreased $24 \mathrm{~h}$ after treatment with ESL, but was similar to control levels $24 \mathrm{~h}$ after exposure to S-Lic. Exposure to R-Lic, CBZ or LTG did not significantly affect the levels of phospho-ERK $1 / 2$, $(p>0.05)$ (Fig. 4C, D, F). Exposure to OXC for 30 or 60 min caused a significant decrease in phosphorylated ERK $1 / 2(61.62 \pm 4.8$ and $58.27 \pm 6.01 \%$, respectively, $p<0.05$ ) (Fig. $4 \mathrm{E}$ ). In contrast, $30 \mathrm{~min}$ after exposure to VPA, there was an increase in phospho-ERK $1 / 2$ to $144.4 \pm 2.6 \%(p<0.05)$ (Fig. $4 \mathrm{G})$. Concerning the activation of Akt, in this study we evaluated possible changes in the phosphorylation of both serine 473 (Ser473) and threonine 308 (Thr308) residues. The results of Western blot analysis indicated significant changes on the levels of phosphorylation only in the Thr308 residue, following exposure of hippocampal neurons to AEDs (Fig. 5). Thus, ESL caused a significant decrease in phospho-Thr308 to $50.2 \pm 4.6 \%(p<0.05)$ after $1 \mathrm{~h}$ of treatment (Fig. 5A). S-Lic produced a similar effect, but earlier, at $30 \mathrm{~min}$ (Fig. 5B). R-Lic only decreased phosphorylation of Thr308 after $24 \mathrm{~h}$ of exposure to the drug (Fig. 5C). CBZ decreased Thr308 phosphorylation $(47.9 \pm 16.8 \%, p<0.01)$ after $60 \mathrm{~min}$ of exposure (Fig. 5D). Exposure to OXC caused a time-dependent decrease in phospho-Thr308, up to $24 \mathrm{~h}$ of exposure $(45.12 \pm 6.5 \%$, of the control, $p<0.01)$ (Fig. 5E). LTG did not significantly alter Akt phosphorylation (Fig. 5F). However, VPA significantly increased the phosphorylation of Thr308 after 60 min of exposure $(202.3 \pm 25.9 \%$, of the control, $p<0.001$ ), but this effect was lost at $24 \mathrm{~h}$ of exposure to VPA (Fig. 5G).

We also analysed the levels of phospho-SAPK/JNK. It was observed that neither ESL nor its metabolites caused changes in the phosphorylation levels of either isoform of SAPK/JNK, p54 and p46 (Fig. 6A-C). The same was observed in cells exposed to OXC (Fig. 6E). On the other hand, CBZ decreased the levels of phospho-p46 by approximately 70\% $(p<0.01)$ up to $60 \mathrm{~min}$ after exposure (Fig. 6D). Exposure to LTG for $60 \mathrm{~min}$ caused a significant increase in the phospho levels of both isoforms $(137.2 \pm 10.5 \%$ for phospho-p54, and $137.5 \pm 9.8 \%$ for phospho-p46, $p<0.05$ ), which remained elevated by 2 -fold after $24 \mathrm{~h}$ exposure $(194.0 \pm 17.6 \%$ for phospho-p54, and $198.8 \pm 28.4 \%$ for phospho-p46, $p<0.001$ ) (Fig. 6F). Exposure to VPA for $24 \mathrm{~h}$ also caused an increase in phospho-p46 to $136.2 \pm 16.8 \%$ of the control ( $p<0.05$ ) (Fig. $6 G$ ).

\section{Discussion}

AEDs interact primarily with neurotransmitters receptors or ion channels, and they may directly or indirectly interfere with intracellular proteins and signaling systems. Also, AEDs can induce neuronal cell death by triggering apoptotic neurodegeneration in 
A. ESL

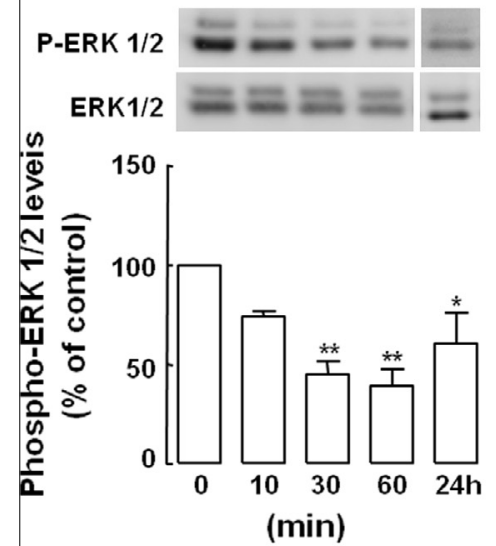

D. $C B Z$

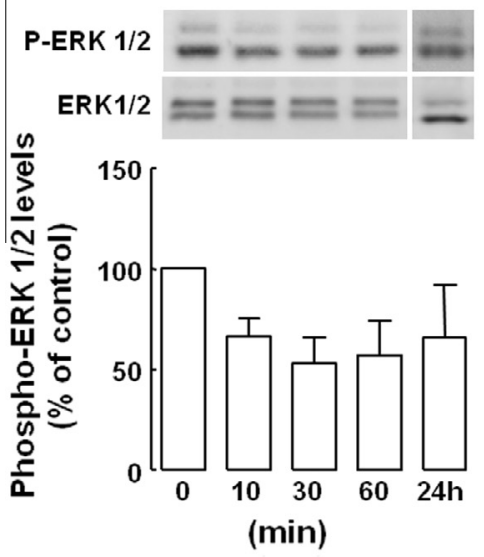

B. S-Lic
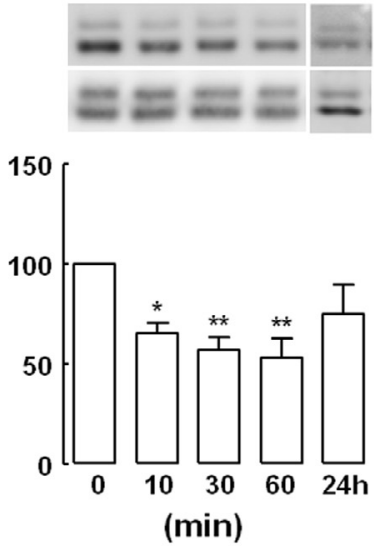

E. OXC
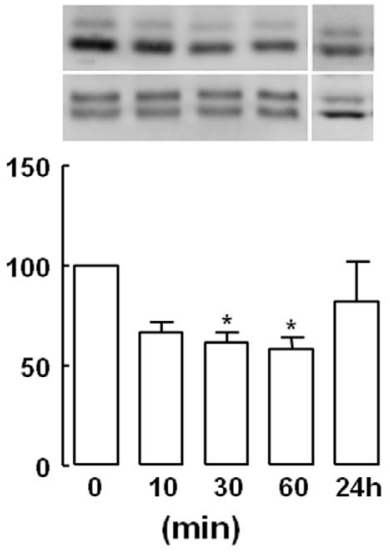

C. R-Lic
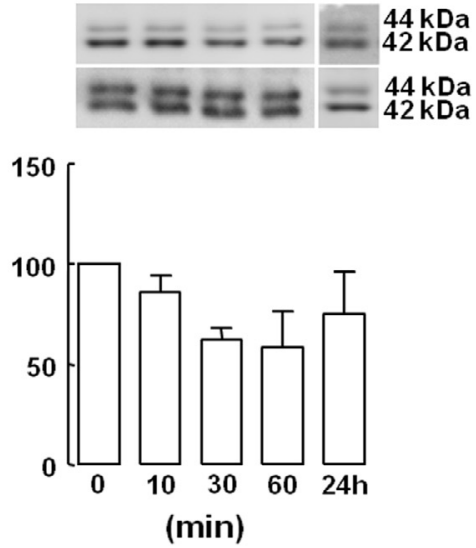

\section{G. VPA}

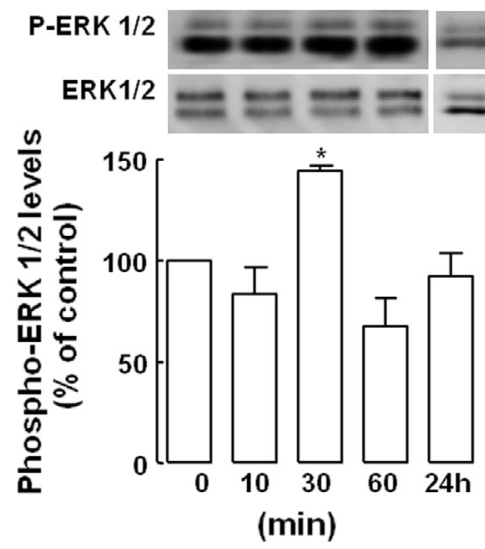

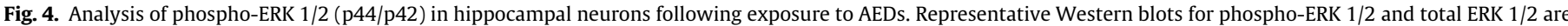

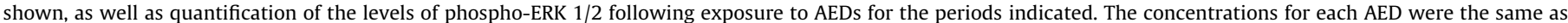

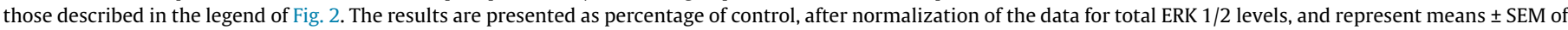

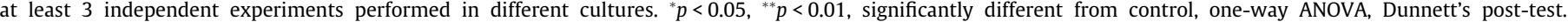
Abbreviations of the AEDs as indicated in the legend of Fig. 1.

developing brain (Bittigau et al., 2002; Ikonomidou et al., 2000; Olney et al., 2002). There is no information about the potential toxic effects triggered by ESL metabolites and by LTG in cultured hippocampal neurons. The present data show that neither ESL nor its metabolites, S-Lic and R-Lic, or LTG, caused any toxicity to cultured hippocampal neurons. OXC was the most toxic compound in all assays, particularly at high concentrations, and VPA also induced the appearance of apoptotic markers in hippocampal cultures.
Exposure to OXC ( 0.1 and $0.3 \mathrm{mM})$ for $24 \mathrm{~h}$ increased cell death in hippocampal neurons. Activation of caspase- 3 and PARP cleavage was also evident following treatment with OXC. However, ESL, S-Lic, R-Lic or LTG had no effect, up to $0.3 \mathrm{mM}$, on the viability of cultured hippocampal neurons, according to the parameters evaluated in this study. OXC stands out as the most toxic drug evaluated, which is in agreement with previous studies in hippocampal neurons (Ambrosio et al., 2000; Araujo et al., 2004). In a previous 
A. ESL

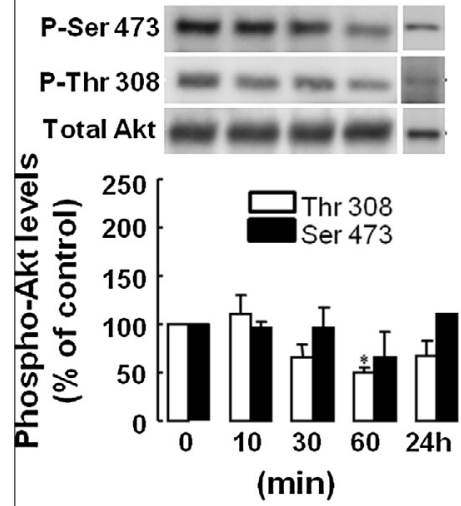

D. $C B Z$

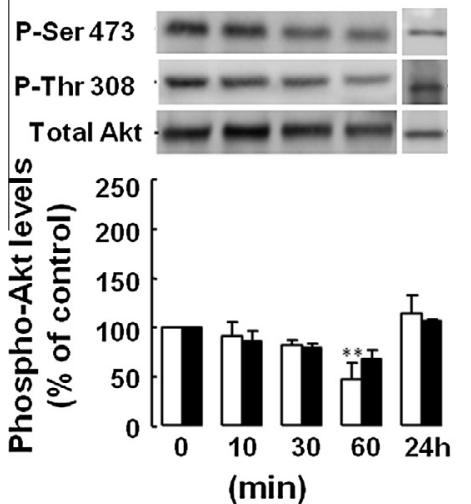

B. S-Lic
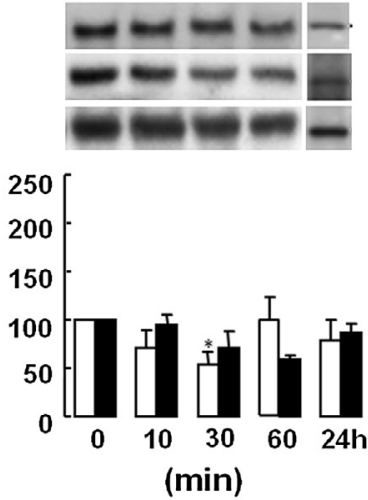

E. OXC
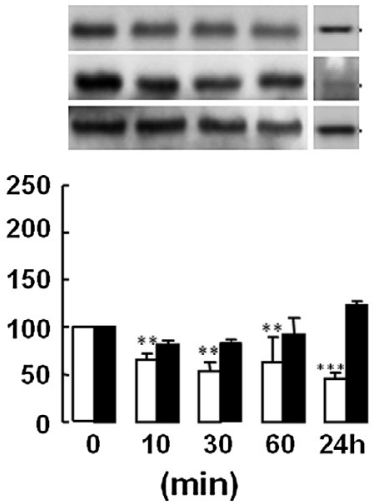

C. R-Lic
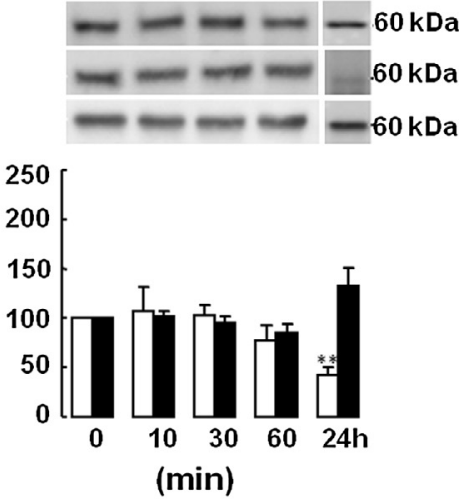

F. LTG
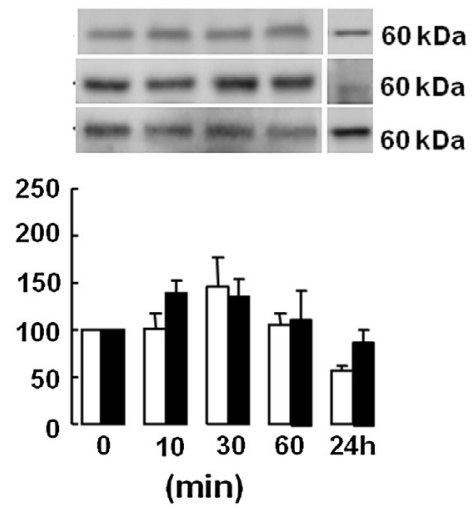

G. VPA

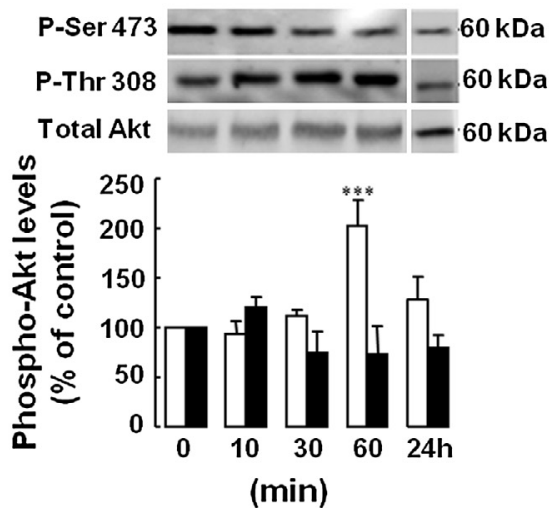

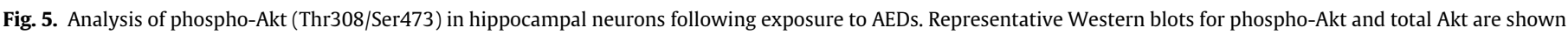

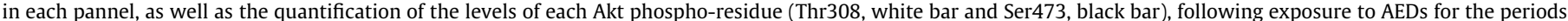

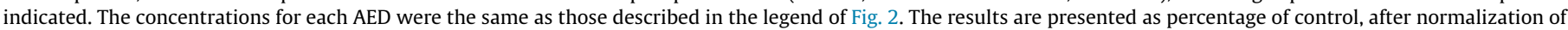

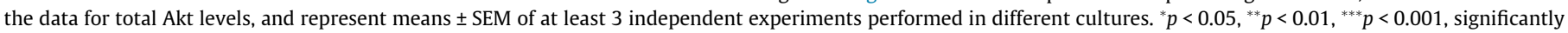
different from control, two-way ANOVA (time and residue as factors), Bonferronis's post-test. Abbreviations of the AEDs as indicated in the legend of Fig. 1.

study, we found that treatment with OXC $(0.3 \mathrm{mM}$, for $24 \mathrm{~h})$ triggered a loss of the mitochondrial membrane potential. Since the release of AIF from the mitochondria and its translocation to the nucleus occurs after mitochondrial depolarization (Zhang et al., 2002), we examined whether AIF could be a player in the toxic effect of OXC in hippocampal neurons. Interestingly, the translocation of AIF to the nuclei of dying hippocampal neurons exposed to OXC was not observed (nor in cells treated with the other AEDs), even though apoptotic nuclei were quite evident in OXC-treated cells. Since this protein does not seem to be involved in the cell death triggered by exposure to OXC in hippocampal neurons, it is plausible that cell death observed after exposure to OXC may be caspase-dependent.
Exposure of hippocampal neurons to OXC $(0.3 \mathrm{mM})$ or VPA ( $3 \mathrm{mM}$ ) caused an increase in caspase- 3 activation, and also in PARP cleavage. However, cell death was not observed after VPA exposure when looking at nuclear condensation/fragmentation, and cell viability was not decreased by this drug. One possible explanation for the lack of cell death (despite some indication of apoptosis such as the presence of cleaved caspase-3) is that caspase- 3 cleavage occurs earlier in the cell death cascade than nuclear condensation and changes in the redox capacity of the cells. Thus, although a clear decrease in cell viability is not yet detected by these methods, caspase- 3 has already been activated and the cell death cascade was set into motion. Stimulation of cell survival pathways concomitantly with cleavage of caspase- 3 may prevent 
A. ESL

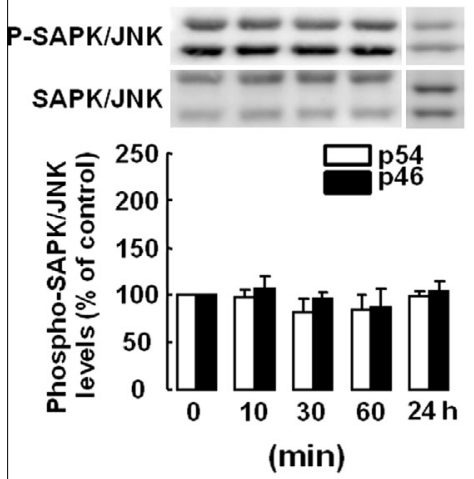

D. $C B Z$

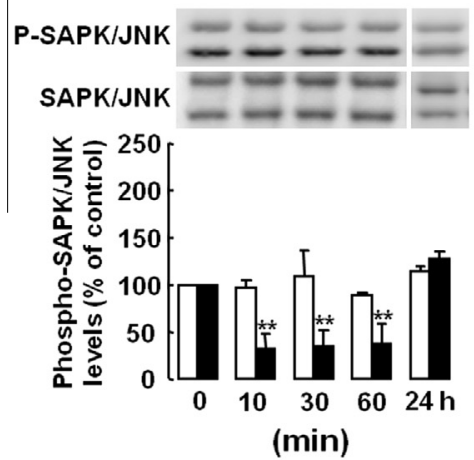

B. S-Lic
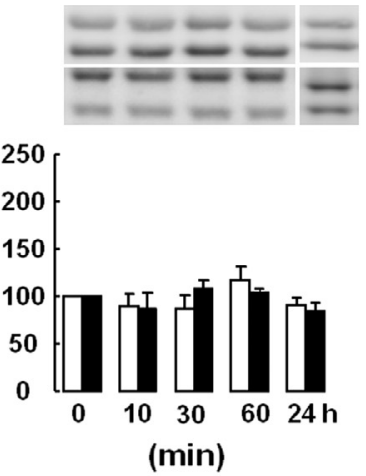

E. OXC

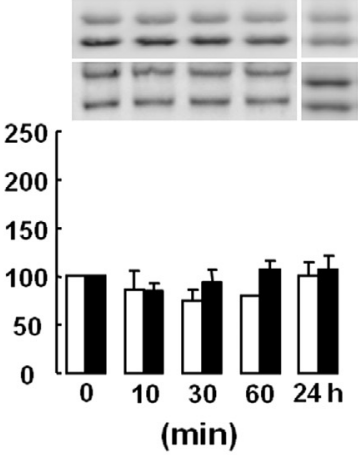

C. R-Lic
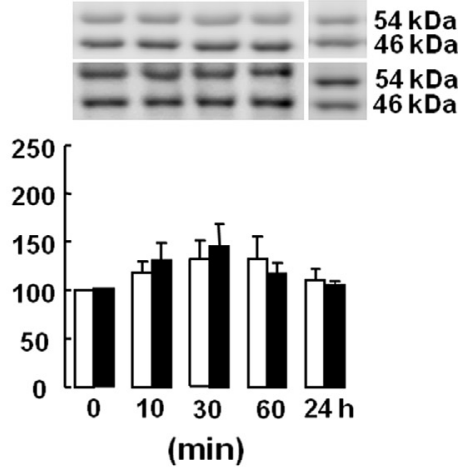

F. LTG

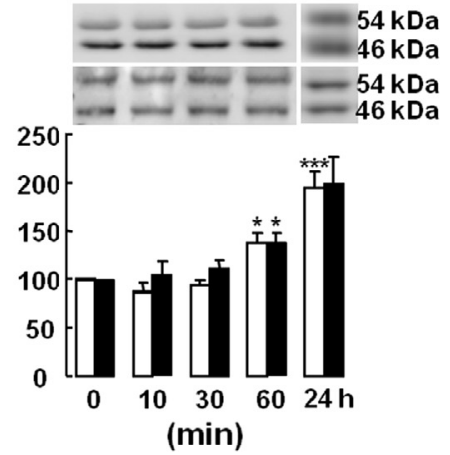

G. VPA
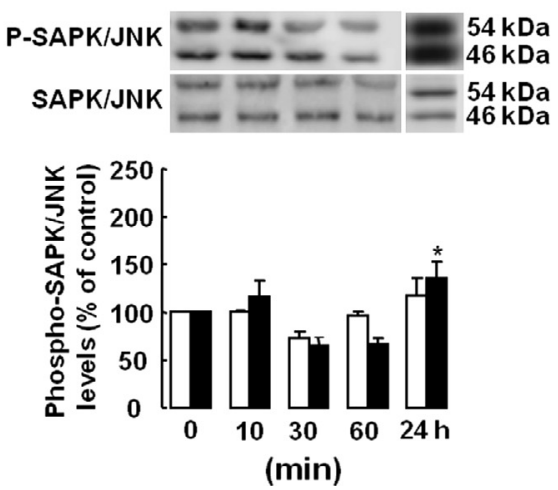

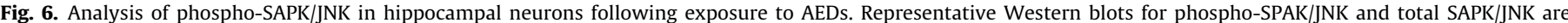

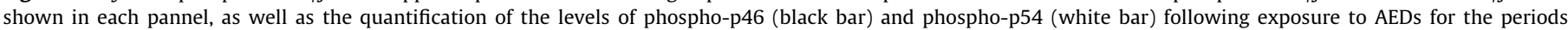

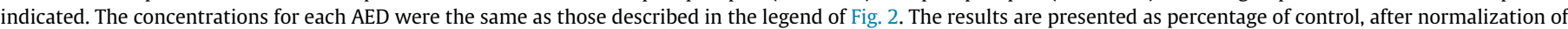

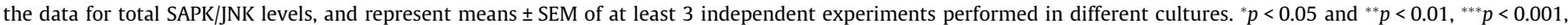
significantly different from control, two-way ANOVA (time and isoforms as factors), Bonferroni's post-test. Abbreviations of the AEDs as indicated in Fig. 1.

cell death; thus, following exposure to VPA, although caspase-3 cleavage is detectable, it is not associated to cell demise.

Mitogen-activated protein kinases (MAPKs) are activated by diverse stimuli such as neurotransmitters, cellular stress and growth factors (Liu et al., 2007). ERK 1/2 (extracellular signal-regulated kinase) and Jun-N-terminal kinase (JNK) also known as stress-activated protein kinase (SAPK) are two subfamilies of MAPKs. The MAPK/ERK pathway among other features is involved in neuronal survival. Hetman and Gozdz (2004) showed that ERK1/2 has a pro-survival activity in neurons (Hetman and Gozdz, 2004; Hetman et al., 1999). On the other hand, it also has a role in apoptosis, which depends on cell type and on the signal that triggers cell death. It was observed that persistent activation of ERK $1 / 2$ contributes to apoptosis in primary cortical neuronal cultures (Satoh et al., 2000; Stanciu et al., 2000). The SAPK/JNK is a central mediator of stress and is essential for the regulation of physiological and pathological processes (Johnson and Nakamura, 2007). It mediates apoptosis by regulation of pro- and anti-apoptotic activity of members of Bcl-2 family and gene transcription (Burke, 2007). PI3K/AKT signaling pathway also plays a role in surviving of neurons by different mechanisms (Dudek et al., 1997; Yao and Cooper, 1995). Akt is a serine/threonine kinase involved in this pathway and when activated it mediates cell survival by inhibition of apoptosis, proliferation and transcription, among other functions (Brazil and Hemmings, 2001), and thus deactivation of Akt accompanies cell death induced by many different agents (Luo et al., 2003). Changes in these signaling pathways reflect an imbalance between neuroprotective and neurodegenerative mechanisms in the brain that can 
induce apoptotic death (Asimiadou et al., 2005; Bittigau et al., 2003).

In this study, we observed that CBZ did not increase neuroprotective signaling, and actually strongly decreased the levels of phospho-SAPK/JNK, and to a lesser degree, also decreased the levels of phospho-Akt. Possibly, for a longer exposure, the toxic effect of CBZ would be more evident and detectable by morphological criteria such as nuclear condensation/fragmentation, as we have found in previous studies (Ambrosio et al., 2000; Araujo et al., 2004). Moreover, dibenz[b,f]azepine derivatives such as OXC, ESL, R-Lic and S-Lic also decreased the levels of phosphorylated forms of ERK 1/2, Akt and SAPK/JNK. OXC strongly decreased the phosphorylation status of ERK $1 / 2$ and Akt. A previous study by Bittigau et al. (2002) suggested that AEDs can induce apoptosis in neurons by inhibiting and decreasing the signaling of survival pathways such as ERK 1/2 and Akt (Bittigau et al., 2002). ESL, S-Lic and RLic also decreased the levels of phosphorylated ERK $1 / 2$ and Akt, however this decrease was lower than that observed with OXC and, furthermore, these drugs did not induce any other signs of neurotoxicity as OXC did. This suggests that ESL metabolites are less deleterious to neuronal cells because they affect the survival pathways to a lower extent than other AEDs, namely OXC. On the other hand, one may speculate that these effects of ESL and its metabolites on ERK $1 / 2$ may constitute a compensatory response mechanism to the marked increases in ERK activation observed at the time of spontaneous seizures. In fact, in an in vivo study, phospho-ERK levels were shown to increase after a behavioural seizure detection (Houser et al., 2008). Inhibiting ERK signaling might be useful for seizure control (Nateri et al., 2007).

Unless metabolic impairment or hepatic failure occurs, it is not likely that OXC will persist in high levels in the plasma, and thus it is not expected that it will impact on the overall survival of neuronal cells in vivo. In fact, at least in humans this AED is readily converted to S-Lic and R-Lic (Almeida and Soares-da-Silva, 2007). Regarding the fact that OXC is a minor metabolite of ESL in humans, OXC accounts for less than $5 \%$ of metabolized ESL, and it is unlikely that high concentrations of OXC as those used in this study will reach the brain. However, in a recent study with healthy volunteers that received ESL or OXC $\left(\right.$ Trileptal $^{\circledR}$ ), the extent of exposure to R-licarbazepine and OXC in plasma and cerebrospinal fluid was approximately fourfold higher with OXC as compared with ESL. Remarkably, a total of 84 and 24 treatment-emergent adverse events (mostly CNS related) were reported with OXC and ESL, respectively (Nunes et al., 2013). This suggests that high OXC exposure may associate with more frequent and marked CNS related adverse events. Similar differences in tolerability between healthy volunteers receiving ESL and oxcarbazepine were reported by Milovan et al. (2010).

It is of interest to mention here that the concentrations of AEDs used in the present in vitro experiments are higher than those found in patients, however they were chosen accordingly to previous studies where a large spectrum of concentrations were used to test effects on cultured neurons (Nonaka et al., 1998; Benes et al., 1999; Ambrosio et al., 2000; Araujo et al., 2004). In particular, the concentrations of OXC used were near to those observed in the plasma of humans (Almeida et al., 2008). Furthermore it is not known whether the chronic use of the drugs in patients may lead to their accumulation in microdomains of the nervous system where higher concentrations than those found in the plasma may be attained.

Interestingly, we observed that LTG strongly increased the phosphorylation of SAPK/JNK in hippocampal neurons, which may indicate that LTG promotes neuronal survival by this pathway, as suggested but not fully explored by Chang and colleagues (Chang et al., 2009). Another study has also demonstrated that LTG does not affect the signaling of ERK $1 / 2$ or Akt (Aubry et al.,
2009), but its effect on the SAPK/JNK pathway had up to now remained unaddressed. Moreover, LTG was shown to be able to prevent staurosporine-induced caspase- 3 activation in a neuronal cell line (Li et al., 2002), for a concentration similar to the one used in this study $(0.3 \mathrm{mM})$. Our results support the possibility that LTG may be a neuroprotective agent, acting through the JNK pathway.

Finally, we observed that VPA stimulated the phosphorylation of ERK $1 / 2$, Akt and SAPK/JNK, which may trigger neuroprotective mechanisms. Our data are in agreement with earlier findings showing that treatment with VPA activates ERK 1/2, Akt and SAPK/JNK, which are ultimately responsible for its neuroprotective effects (Chuang, 2005; Di Daniel et al., 2005; Mora et al., 1999).

In summary, it is shown that ESL and its metabolites, S-Lic and $\mathrm{R}$-Lic, up to $0.3 \mathrm{mM}$, do not induce neurotoxic effects in hippocampal neurons in vitro, and the observed inhibitory effects on MAPK/ ERK pathway may be beneficial in vivo to face the overactivation of ERK1/2 that may occur during spontaneous seizures. CBZ and LTG were not toxic to cultured neurons at the concentrations tested (0.03-0.3 mM), and LTG may exert neuroprotective effects through the activation of the JNK pathway. Treatment with OXC or VPA induced the appearance of markers related to cell death, and OXC was the most toxic drug.

\section{Conflict of interest}

P. Soares-da-Silva is the Head of Research \& Development at BIAL-Portela \& C ${ }^{a}$, S.A., S. Mamede do Coronado, Portugal. The remaining authors have no conflicts of interest.

This study was supported by BIAL-Portela \& $C^{a}$, S.A., S. Mamede do Coronado, Portugal, which holds commercial rights for ESL.

\section{Acknowledgements}

This work was funded by BIAL-Portela \& Caㅗ , S.A., S. Mamede do Coronado, Portugal. MIM and BPC were supported by Foundation for Science and Technology, Portugal (SFRH/BD/38127/2007 and SFRH/BD/17196/2004).

We confirm that we have read the Journal's position on issues involved in ethical publication and affirm that this report is consistent with those guidelines.

\section{Appendix A. Supplementary material}

Supplementary data associated with this article can be found, in the online version, at http://dx.doi.org/10.1016/j.tiv.2013.09.008.

\section{References}

Albani, F., Riva, R., Baruzzi, A., 1995. Carbamazepine clinical pharmacology: a review. Pharmacopsychiatry 28, 235-244.

Almeida, L., Soares-da-Silva, P., 2007. Eslicarbazepine acetate (BIA 2-093). Neurotherapeutics 4, 88-96.

Almeida, L., Falcao, A., Maia, J., Mazur, D., Gellert, M., Soares-da-Silva, P., 2005. Single-dose and steady-state pharmacokinetics of eslicarbazepine acetate (BIA 2-093) in healthy elderly and young subjects. J. Clin. Pharmacol. 45, 1062-1066.

Almeida, L., Potgieter, J.H., Maia, J., Potgieter, M.A., Mota, F., Soares-da-Silva, P., 2008. Pharmacokinetics of eslicarbazepine acetate in patients with moderate hepatic impairment. Eur. J. Clin. Pharmacol. 64, 267-273.

Alves, G., Figueiredo, I., Castel-Branco, M., Loureiro, A., Falcao, A., Caramona, M., 2007. Simultaneous and enantioselective liquid chromatographic determination of eslicarbazepine acetate, S-licarbazepine, R-licarbazepine and oxcarbazepine in mouse tissue samples using ultraviolet detection. Anal. Chim. Acta 596, 132-140.

Ambrosio, A.F., Silva, A.P. Araujo, I., Malva, J.O., Soares-da-Silva, P. Carvalho, A.P. Carvalho, C.M., 2000. Neurotoxic/neuroprotective profile of carbamazepine, oxcarbazepine and two new putative antiepileptic drugs, BIA 2-093 and BIA 2024. Eur. J. Pharmacol. 406, 191-201.

Araujo, I.M., Ambrosio, A.F., Leal, E.C., Verdasca, M.J., Malva, J.O., Soares-da-Silva, P., Carvalho, A.P., Carvalho, C.M., 2004. Neurotoxicity induced by antiepileptic drugs in cultured hippocampal neurons: a comparative study between 
carbamazepine, oxcarbazepine, and two new putative antiepileptic drugs, BIA 2-024 and BIA 2-093. Epilepsia 45, 1498-1505.

Araujo, I.M., Carreira, B.P., Pereira, T., Santos, P.F., Soulet, D., Inacio, A., Bahr, B.A., Carvalho, A.P., Ambrosio, A.F., Carvalho, C.M., 2007. Changes in calcium dynamics following the reversal of the sodium-calcium exchanger have a key role in AMPA receptor-mediated neurodegeneration via calpain activation in hippocampal neurons. Cell Death Diff. 14, 1635-1646.

Asimiadou, S., Bittigau, P., Felderhoff-Mueser, U., Manthey, D., Sifringer, M., Pesditschek, S., Dzietko, M., Kaindl, A.M., Pytel, M., Studniarczyk, D., Mozrzymas, J.W., Ikonomidou, C., 2005. Protection with estradiol in developmental models of apoptotic neurodegeneration. Ann. Neurol. 58, 266276.

Aubry, J.M., Schwald, M., Ballmann, E., Karege, F., 2009. Early effects of mood stabilizers on the Akt/GSK-3beta signaling pathway and on cell survival and proliferation. Psychopharmacology 205, 419-429.

Benes, L., Parada, A., Figueiredo, A.A., Alves, P.C., Freitas, A.P., Learmonth, D.A., Cunha, R.A., Garret, J., Soares-da-Silva, P., 1999. Anticonvulsant and sodium channel-blocking properties of novel 10,11-dihydro-5H-dibenz[b, f]azepine-5carboxamide derivatives. J. Med. Chem. 42, 2582-2587.

Bialer, M., 2006. New antiepileptic drugs that are second generation to existing antiepileptic drugs. Exp. Opin. Investig. Drugs 15, 637-647.

Bittigau, P., Sifringer, M., Genz, K., Reith, E., Pospischil, D., Govindarajalu, S., Dzietko, M., Pesditschek, S., Mai, I., Dikranian, K., Olney, J.W., Ikonomidou, C., 2002. Antiepileptic drugs and apoptotic neurodegeneration in the developing brain. Proc. Natl. Acad. Sci. USA 99, 15089-15094.

Bittigau, P., Sifringer, M., Ikonomidou, C., 2003. Antiepileptic drugs and apoptosis in the developing brain. Ann. N.Y. Acad. Sci. 993, 103-114, discussion 123-104.

Brady, K., Hebeisen, S., Konrad, D., Soares-da-Silva, P., 2011. The effects of eslicarbazepine, R-licarbazepine, oxcarbazepine and carbamazepine on ion transmission $\mathrm{Ca}_{\mathrm{v}} 3.2$ channels. Epilepsia 52 (Suppl. 6), 260.

Brazil, D.P., Hemmings, B.A., 2001. Ten years of protein kinase B signaling: a hard Akt to follow. Trends Biochem. Sci. 26, 657-664.

Brewer, G.J., Torricelli, J.R., Evege, E.K., Price, P.J., 1993. Optimized survival of hippocampal neurons in B27-supplemented Neurobasal, a new serum-free medium combination. J. Neurosci. Res. 35, 567-576.

Burke, R.E., 2007. Inhibition of mitogen-activated protein kinase and stimulation of Akt kinase signaling pathways: two approaches with therapeutic potential in the treatment of neurodegenerative disease. Pharmacol. Ther. 114, 261-277.

Chang, Y.C., Rapoport, S.I., Rao, J.S., 2009. Chronic administration of mood stabilizers upregulates BDNF and bcl-2 expression levels in rat frontal cortex. Neurochem. Res. 34, 536-541.

Chateauvieux, S., Morceau, F., Dicato, M., Diederich, M., 2010. Molecular and therapeutic potential and toxicity of valproic acid. J. Biomed. Biotechnol..

Chuang, D.M., 2005. The antiapoptotic actions of mood stabilizers: molecular mechanisms and therapeutic potentials. Ann. N.Y. Acad. Sci. 1053, 195-204.

Di Daniel, E., Mudge, A.W., Maycox, P.R., 2005. Comparative analysis of the effects of four mood stabilizers in SH-SY5Y cells and in primary neurons. Bipolar. Disord. 7, 33-41.

Dudek, H., Datta, S.R., Franke, T.F., Birnbaum, M.J., Yao, R., Cooper, G.M., Segal, R.A., Kaplan, D.R., Greenberg, M.E., 1997. Regulation of neuronal survival by the serine-threonine protein kinase Akt. Science 275, 661-665.

Elger, C.E., Bauer, J., 1998. New antiepileptic drugs in epileptology. Neuropsychobiology 38, 145-148.

Elger, C., Halasz, P., Maia, J., Almeida, L., Soares-da-Silva, P., 2009. Efficacy and safety of eslicarbazepine acetate as adjunctive treatment in adults with refractory partial-onset seizures: a randomized, double-blind, placebo-controlled, parallel-group phase III study. Epilepsia 50, 454-463.

Gao, X.M., Margolis, R.L., Leeds, P., Hough, C., Post, R.M., Chuang, D.M., 1995. Carbamazepine induction of apoptosis in cultured cerebellar neurons: effects of $\mathrm{N}$-methyl-D-aspartate, aurintricarboxylic acid and cycloheximide. Brain Res. 703, 63-71.

Hebeisen, S., Brady, K., Konrad, D., Soares-da-Silva, P., 2011. Inhibitory effects of eslicarbazepine acetate and its metabolites against neuronal voltage-gated sodium channels. Epilepsia 52 (Suppl. 6), 257-258.

Hetman, M., Gozdz, A., 2004. Role of extracellular signal regulated kinases 1 and 2 in neuronal survival. Eur. J. Biochem. 271, 2050-2055.

Hetman, M., Kanning, K., Cavanaugh, J.E., Xia, Z., 1999. Neuroprotection by brainderived neurotrophic factor is mediated by extracellular signal-regulated kinase and phosphatidylinositol 3-kinase. J. Biol. Chem. 274, 22569-22580.

Houser, C.R., Huang, C.S., Peng, Z., 2008. Dynamic seizure-related changes in extracellular signal-regulated kinase activation in a mouse model of temporal lobe epilepsy. Neuroscience 156, 222-237.

Hsieh, J., Nakashima, K., Kuwabara, T., Mejia, E., Gage, F.H., 2004. Histone deacetylase inhibition-mediated neuronal differentiation of multipotent adult neural progenitor cells. Proc. Natl. Acad. Sci. USA 101 (47), 16659-16664.

Ikonomidou, C., Stefovska, V., Turski, L., 2000. Neuronal death enhanced by Nmethyl-D-aspartate antagonists. Proc. Natl. Acad. Sci. USA 97, 12885-12890.

Johannessen, C.U., Johannessen, S.I., 2003. Valproate: past, present, and future. CNS Drug. Rev. 9, 199-216.

Johannessen Landmark, C., Patsalos, P.N., 2010. Drug interactions involving the new second- and third-generation antiepileptic drugs. Exp. Rev. Neurother. 10, 119140.

Johnson, G.L., Nakamura, K., 2007. The c-jun kinase/stress-activated pathway: regulation, function and role in human disease. Biochim. Biophys. Acta 1773, 1341-1348.
Joza, N., Susin, S.A., Daugas, E., Stanford, W.L., Cho, S.K., Li, C.Y., Sasaki, T., Elia, A.J., Cheng, H.Y., Ravagnan, L., Ferri, K.F., Zamzami, N., Wakeham, A., Hakem, R., Yoshida, H., Kong, Y.Y., Mak, T.W., Zuniga-Pflucker, J.C., Kroemer, G., Penninger, J.M., 2001. Essential role of the mitochondrial apoptosis-inducing factor in programmed cell death. Nature 410, 549-554.

Katz, I., Kim, J., Gale, K., Kondratyev, A., 2007. Effects of lamotrigine alone and in combination with MK-801, phenobarbital, or phenytoin on cell death in the neonatal rat brain. J. Pharmacol. Exp. Ther. 322, 494-500.

Kuo, C.C., 1998. A common anticonvulsant binding site for phenytoin, carbamazepine, and lamotrigine in neuronal Na+ channels. Mol. Pharmacol. 54, 712-721.

Landmark, C.J., Johannessen, S.I., 2008. Modifications of antiepileptic drugs for improved tolerability and efficacy. Perspect Medicin. Chem. 2, 21-39.

Li, X., Bijur, G.N., Jope, R.S., 2002. Glycogen synthase kinase-3beta, mood stabilizers, and neuroprotection. Bipolar. Disord. 4, 137-144.

Liu, Y., Shepherd, E.G., Nelin, L.D., 2007. MAPK phosphatases-regulating the immune response. Nat. Rev. Immunol. 7, 202-212.

Loring, D.W., Marino, S., Meador, K.J., 2007. Neuropsychological and behaviora effects of antiepilepsy drugs. Neuropsychol. Rev. 17, 413-425.

Loscher, W., 2002. Basic pharmacology of valproate: a review after 35 years of clinical use for the treatment of epilepsy. CNS Drugs 16, 669-694.

Luo, H.R., Hattori, H., Hossain, M.A., Hester, L., Huang, Y., Lee-Kwon, W., Donowitz, M., Nagata, E., Snyder, S.H., 2003. Akt as a mediator of cell death. Proc. Natl. Acad. Sci. USA 100, 11712-11717.

Manent, J.B., Jorquera, I., Franco, V., Ben-Ari, Y., Perucca, E., Represa, A., 2008 Antiepileptic drugs and brain maturation: fetal exposure to lamotrigine generates cortical malformations in rats. Epilepsy Res. 78, 131-139.

McCormack, P.L., Robinson, D.M., 2009. Eslicarbazepine acetate. CNS Drugs 23, 7179.

Milovan, D., Almeida, L., Romach, M.K., Nunes, T., Rocha, J.F., Sokowloska, M., Sellers, E.M., Soares-da-Silva, P., 2010. Effect of eslicarbazepine acetate and oxcarbazepine on cognition and psychomotor function in healthy volunteers. Epilepsy Behav. 18, 366-373.

Mora, A., Gonzalez-Polo, R.A., Fuentes, J.M., Soler, G., Centeno, F., 1999. Different mechanisms of protection against apoptosis by valproate and $\mathrm{Li}^{+}$. Eur. J. Biochem. 266, 886-891.

Nateri, A.S., Raivich, G., Gebhardt, C., Da Costa, C., Naumann, H., Vreugdenhil, M. Makwana, M., Brandner, S., Adams, R.H., Jefferys, J.G., Kann, O., Behrens, A., 2007. ERK activation causes epilepsy by stimulating NMDA receptor activity. EMBO J. 26, 4891-4901.

Nonaka, S., Katsube, N., Chuang, D.M., 1998. Lithium protects rat cerebellar granule cells against apoptosis induced by anticonvulsants, phenytoin and carbamazepine. J. Pharmacol. Exp. Ther. 286, 539-547.

Nunes, T., Rocha, J.F., Falcao, A., Almeida, L., Soares-da-Silva, P., 2013. Steady-state plasma and cerebrospinal fluid pharmacokinetics and tolerability of eslicarbazepine acetate and oxcarbazepine in healthy volunteers. Epilepsia 54, $108-116$.

Olney, J.W., Wozniak, D.F., Jevtovic-Todorovic, V., Farber, N.B., Bittigau, P. Ikonomidou, C., 2002. Drug-induced apoptotic neurodegeneration in the developing brain. Brain Pathol. 12, 488-498.

Parada, A., Soares-da-Silva, P., 2002. The novel anticonvulsant BIA 2-093 inhibits transmitter release during opening of voltage-gated sodium channels: a comparison with carbamazepine and oxcarbazepine. Neurochem. Int. 40 435-440.

Pennell, P.B., 2008. Antiepileptic drugs during pregnancy: what is known and which AEDs seem to be safest? Epilepsia 49 (Suppl 9), 43-55.

Perucca, E., 2002. Overtreatment in epilepsy: adverse consequences and mechanisms. Epilepsy Res. 52, 25-33.

Rogawski, M.A., Loscher, W., 2004. The neurobiology of antiepileptic drugs for the treatment of nonepileptic conditions. Nat. Med. 10, 685-692.

Satoh, T., Nakatsuka, D., Watanabe, Y., Nagata, I., Kikuchi, H., Namura, S., 2000 Neuroprotection by MAPK/ERK kinase inhibition with U0126 against oxidative stress in a mouse neuronal cell line and rat primary cultured cortical neurons. Neurosci. Lett. 288, 163-166.

Stanciu, M., Wang, Y., Kentor, R., Burke, N., Watkins, S., Kress, G., Reynolds, I., Klann, E., Angiolieri, M.R., Johnson, J.W., DeFranco, D.B., 2000. Persistent activation of ERK contributes to glutamate-induced oxidative toxicity in a neuronal cell line and primary cortical neuron cultures. J. Biol. Chem. 275, 12200-12206.

Stefan, H., Feuerstein, T.J., 2007. Novel anticonvulsant drugs. Pharmacol. Ther. 113, $165-183$.

Wang, C.C., Chen, P.S., Hsu, C.W., Wu, S.J., Lin, C.T., Gean, P.W., 2012. Valproic acid mediates the synaptic excitatory/inhibitory balance through astrocytes - a preliminary study. Prog. Neuropsychopharmacol. Biol. Psychiatry 37, 111-120.

Willmore, L.J., 2005. Antiepileptic drugs and neuroprotection: current status and future roles. Epilepsy Behav. 7 (Suppl 3), S25-28.

Xie, X., Lancaster, B., Peakman, T., Garthwaite, J., 1995. Interaction of the antiepileptic drug lamotrigine with recombinant rat brain type IIA $\mathrm{Na}+$ channels and with native $\mathrm{Na}+$ channels in rat hippocampal neurones. Pflugers Arch. 430, 437-446.

Yao, R., Cooper, G.M., 1995. Requirement for phosphatidylinositol-3 kinase in the prevention of apoptosis by nerve growth factor. Science 267, 2003-2006.

Zhang, X., Chen, J., Graham, S.H., Du, L., Kochanek, P.M., Draviam, R., Guo, F., Nathaniel, P.D., Szabo, C., Watkins, S.C., Clark, R.S., 2002. Intranuclear localization of apoptosis-inducing factor (AIF) and large scale DNA fragmentation after traumatic brain injury in rats and in neuronal cultures exposed to peroxynitrite. J. Neurochem. 82, 181-191. 